2016-10

\title{
Developmental differences in children's interpersonal emotion regulation
}

\author{
Lopez-Perez, B
}

http://hdl.handle.net/10026.1/8223

10.1007/s11031-016-9569-3

Motivation and Emotion

Springer Verlag

All content in PEARL is protected by copyright law. Author manuscripts are made available in accordance with publisher policies. Please cite only the published version using the details provided on the item record or document. In the absence of an open licence (e.g. Creative Commons), permissions for further reuse of content should be sought from the publisher or author. 


\section{INTERPERSONAL EMOTION REGULATION}

\section{Running head: INTERPERSONAL EMOTION REGULATION}

Developmental Differences in Children's Interpersonal Emotion Regulation

Belén López-Pérez, Ellie L. Wilson, Giulia Dellaria \& Michaela Gummerum University of Plymouth

Correspondence concerning this article should be addressed to Belén López-Pérez, School of Psychology, Cognition Institute, University of Plymouth, Drake Circus, Plymouth, PL4 8AA, UK. Electronic mail may be sent to belen.lopez-perez@plymouth.ac.uk

Accepted: 18/07/2016

Embargo period: No current embargo required, author can archive post-print (final draft postrefereeing)

This is the peer-reviewed version of the following article: López-Pérez, B., Wilson, E., Dellaria, G.,\& Gummerum, M. (in press). Developmental differences in children's interpersonal emotion regulation. Motivation and Emotion. 40, 767-780. DOI 10.1007/s11031-016-9569-3, which has been published by Springer. This article may not exactly replicate the final version published. It is not the copy of record. 


\begin{abstract}
Previous research on interpersonal emotion regulation (ER) in childhood has been rather unsystematic, focusing mainly on children's prosocial behaviour, and has been conducted in the absence of an integrative emotion theoretical framework. The present research relied on the interpersonal affect classification proposed by Niven, Totterdell, and Holman (2009) to investigate children's use of different interpersonal ER strategies. The study drew on two samples: 180 parents of children aged between 3 and 8 years reported about a situation where their child was able to change what another person was feeling in order to make them feel better. In addition, 126 children between 3- and 8-years old answered two questions about how they could improve others' mood. Results from both samples showed age differences in children's use of interpersonal ER strategies. As expected, 'affective engagement' (i.e., focusing on the person or the problem) and 'cognitive engagement' (i.e., appraising the situation from a different perspective) were mainly used by 7-8 years-old, whereas 'attention' (i.e., distracting and valuing) was most used by 3-4 and 5-6 years-old. 'Humor' (i.e., laughing with the target) remained stable across the different age groups. The present research provides more information about the developmental patterns for each specific interpersonal emotion regulation strategy.
\end{abstract}

Keywords: interpersonal emotion regulation; childhood; regulation strategies. 


\section{Developmental Differences in Children's Interpersonal Emotion Regulation}

Emotion regulation (ER) refers to a set of processes aimed at initiating, inhibiting, or modifying an individual's positive or negative emotional experience and expression (Gross, 2007). Although research on ER has traditionally focused on the different strategies a person may use to change their own emotions (i.e., intrapersonal ER; see Eisenberg, 2000; Gross, 2007; Thompson, 1994), more recently research started to investigate interpersonal ER (Parkinson, Fischer, \& Manstead, 2005). The term interpersonal ER captures related but distinct phenomena, including an individual's desire to share their emotional states with others (i.e., social sharing, Rimé, 2007), the attenuation of one's own negative affect in the presence of others (Coan, 2011), and the motivation to change others' affective states (Niven, Totterdell, \& Holman, 2009; Niven, Totterdell, Stride, \& Holman, 2011). This paper focused on the latter phenomenon and investigated the different strategies a person (children in this case) uses to change the feelings of others.

\section{Definition of interpersonal ER strategies}

Only recently have interpersonal ER strategies been integrated into an overarching classification system. The interpersonal affect classification (IAC; see Niven et al., 2009) proposes that people use specific emotion regulation strategies to modify others' emotions. Niven et al. (2009) differentiate between affect improving (i.e., any strategy to lighten another's mood) and affect worsening strategies. Affect improving strategies include affective engagement (i.e., engaging directly with the target's feelings through listening, talking about the target's situation, reminding the target they did fine before, etc.), cognitive engagement (i.e., changing the way a target thinks about a situation through highlighting others' support, rationalizing, etc), humor (i.e., improving the target's mood through acting silly, laughing, etc.), and attention (i.e., any action that implies giving the target consideration). Concerning affect worsening, the model differentiates between negative engagement (i.e., involving the 
target with a situation or affective state to worsen his or her affect) and rejection strategies (i.e., snubbing of the target). Because of its integrative nature (i.e., including under a category phenomena that received different names in the literature), this model provides an ideal framework to study developmental differences in the use of interpersonal affect improvement strategies.

\section{Empathy, prosocial behaviour, and interpersonal ER}

Although some facets of interpersonal affect-improving ER seem similar to empathy or prosocial behaviour they are related but different processes (Salovey \& Mayer, 1990). Empathy involves understanding a target's state and one's own feelings towards that target (Batson, 2011; Davis, 1994), whereas interpersonal ER is any action aimed at improving someone's mood or emotional state (Niven et al., 2009). Zaki and Williams (2013) conceptualized empathy as a necessary antecedent for interpersonal affect improvement. One has to perceive and understand how others are feeling (cognitive empathy/perspective-taking) and feel sorry for them (affective empathy/empathic concern) to improve their feelings (interpersonal affect improvement). However, people may understand how others are feeling, experience compassion but still do not do anything to improve others' mood.

Prosocial behaviour differs from interpersonal affect-improving in other important ways. Prosocial behaviour may include any kind of action in which the ultimate goal is to increase someone's well-being (Batson, 2011). Prosocial behaviour may be further distinguished depending on the aim of this action: helping is intended to alleviate an instrumental need, sharing aims to alleviate a material need, and comforting is intended to alleviate an emotional need through recognizing and responding to another's negative affective state (Eisenberg \& Fabes, 1998; Roberts \& Strayer, 1996). According to Dunfield (2014), these three different types of prosocial behaviour may co-occur. For example, when perceiving someone in distress we may provide a treat (sharing) or help them to accomplish a 
task (helping) to make them feel better (comforting). Thus, taken together all these prosocial behaviours aim to provide a benefit to another individual but they are different in the specific need targeted.

Among the different prosocial behaviours described, comforting is most similar to interpersonal affect-improving, as it aims to target an emotional need, unlike helping and sharing (see Figure 1). Helping and sharing could only be equivalent to interpersonal ER when the final goal is to improve or worsen someone's mood (see Figure 1). In this sense, providing something material or helping someone to accomplish a task could be forms of interpersonal ER if the final goal is to change the target's mood (see Figure 1).

\section{Interpersonal ER in childhood}

Evidence from the few studies on interpersonal ER (particularly comforting) in childhood has shown that from early to middle childhood (2-7 years old) children use different behaviours, such as hugs or soothing touches, to comfort others (Farver \& Branstetter, 1994; Persson, 2005). They may also present comforting objects (e.g., teddy bears) and recruit adults to help provide aid (Eisenberg \& Fabes, 1998). From middle childhood to early adolescence (ages 8-14) the most commonly used peer comforting strategies include sympathy (expressing compassion and understanding), advice (recommending actions to take in response to the problem), optimism (expressing reassurance or projecting a positive outcome), companionship (offers of shared activity), account (explaining the distressing event, including validation of explanations or excuses offered by the distressed other), and minimization (treating the problem or feelings as insignificant). Children at these ages may also try to distract their distressed peers (changing the subject or otherwise diverting attention from the problem) (Burleson, 1982; Denton \& Zarbatany, 1996; Dooley, Whalen, \& Flowers, 1978; Eisenberg, Fabes, Karbon, \& Murphy, 1996; Hoffner \& Haefner, 1997; McCoy \& Masters, 1985; Ritter, 1979; Rose \& Asher, 2004). Concerning age 
differences in the use of concrete interpersonal affect-improving ER strategies, research has shown that affection display (i.e., hugs) (labelled as 'attention' in Niven et al.'s model) and talking about problems (labelled as 'affective engagement' in Niven et al.'s model) increase with age, whereas material giving (labelled as 'attention' in Niven et al.'s model) decreases (McCoy \& Masters, 1985). Furthermore, research focused on the influence of expressive behaviours to change others' feelings (i.e., smiling) has found that older children tend to use this strategy more than younger children (Saarni, 1992).

Although this research constituted a first step in the depiction of different interpersonal ER strategies in children, the classifications were made without relying on a solid emotion-research background. According to contemporary ER research on the IAC (Niven et al., 2009), all the strategies depicted previously in the literature can be grouped in different categories. For example, optimism can be grouped in 'affective engagement' if the aim is to reassure the target that everything will be fine. However, it may be classified as 'cognitive engagement' if the aim is to make the target think in more positive terms. From the different categories suggested in the IAC model, 'humor' has been rarely explored in previous developmental studies. Thus, relying on the IAC will be helpful in conducting more systematic research on the use of different strategies across development. It will allow comparing findings across studies and age groups.

Potential age differences in the use of interpersonal ER strategies might be due to developmental changes in social-cognitive capacities. According to Dunfield (2014), changing someone's mood requires the ability to represent another's emotional state and to identify and discriminate between different emotional experiences. Although children can discriminate emotional states from around three months of age (Grossmann, 2010), it is not until three years of age that children are able to explicitly identify concrete emotions in others (e.g., Widen \& Russell, 2003). As acknowledge by Hoffman (1982, 2000), appropriate 
interpersonal ER additionally requires the capacity to identify the cause of another's emotional state (Saarni, Campos, Camras \& Witherington, 2006; Weina, Yuija \& Liang, 2011). It is not until the age of 3 that children are able to make accurate predictions of situations that may lead to joy. However, only by age 4 or 5 do children generalize those predictions to the emotions of anger, fear or surprise (Widen \& Russell, 2003). Given the changes in the different socio-cognitive skills mentioned we expected developmental differences in the use of different interpersonal ER strategies.

\section{The present research}

Our research contributes to the existing literature by assessing age differences in the use of distinct theoretically-defined interpersonal affect improvement ER strategies. Using a sound theoretical model which consolidates strategies (it groups similar strategies under a single category) allows researchers to identify more easily and effectively whether variables such as age or gender affect interpersonal ER.

Furthermore, our research contributes to the existing literature on developmental changes in ER, as it will add more information about normative age-related interpersonal affect improvement ER strategies. Previous research on intrapersonal ER (i.e., the use of any strategy to change one's own mood) has shown significant differences in the use of concrete strategies from early childhood to late adulthood (e.g., Roque \& Verissimo, 2011; Zimmermann \& Iwarski, 2014). However, similar information concerning developmental differences in interpersonal ER is scarce and does not allow for drawing theoretical models.

Consequently, the present study examined age differences in the use of specific interpersonal ER strategies, relying on Niven et al.'s (2009) model. Three- to 8-year-old children's interpersonal ER strategies were assessed using parent-report (sample 1) and child report (sample 2) procedures. We focused on children aged 3- to 8-years-old because 
previous research has shown that at these ages children tend to use a greater variety of interpersonal ER strategies (Persson, 2005; Rose \& Asher, 2004). We also selected this age range as at the age of 3 children start recognising concrete emotions in others, and they also start identifying the causes linked to those emotional experiences, which is one necessary antecedent of interpersonal ER. We decided to put the upper age limit at 8 years as previous studies have shown that 7-8 year olds do not differ from older children in their performance in intrapersonal ER tasks (Simonds, Kieras, Rueda, \& Rothbart, 2007).

In our first sample parents were asked to report about a situation where their child was able to improve another person's feelings/mood. While recalling could be potentially difficult for parents (Levine, Stein, \& Liwag, 1999), parental reports seem to be a valid technique when assessing children younger than seven years old (Bilancia \& Rescorla, 2010; Blandon, Calkins, Keane \& O’ Brien, 2008). Furthermore, previous research on children's emotional responses using parents' reports have found good concordance between parents' and children's responses when reporting about emotionality and regulation (e.g., Eisenberg, Sephard, Fabes, Murphy \& Guthrie, 1998). In our second sample children were asked to report what they would do to improve another person's feelings in a general and in a more specific situation.

We predicted different developmental patterns for each of the four interpersonal ER strategies. The strategy 'affective engagement' entails an active commitment to the target's feelings through active listening, talking to the target, or understanding that the target has stable positive characteristics (Niven et al., 2009). These skills involve being able to represent others' emotional states, as well as emotion understanding, as engaging with the emotional state of others requires understanding not only the emotional experience of another person but also the causes and consequences of it. Since these skills improve with age (e.g., Payton, Wardlaw, Grazyk, Bloodworth, Tompsett, \& Weissberg, 2000; Rholes \& Ruble, 1984) we 
expected that affective engagement strategies would be used more by 7-8 year-olds than 5-6 year-olds and 3-4-year-olds.

'Cognitive engagement' involves changing the way the target thinks about a situation (Gross, 2007). A child's ability to use cognitive change depends on their developing representations of emotions (i.e., the causes and consequences of these emotional responses) (e.g. Stegge, Terwogt, Reijnjes \& Van Tijen, 2004). Representation of emotions start at the age of 4 to 5 years-old (Denham et al., 2012) when children begin to understand the existence of mixed emotions (e.g. Larsen, To, \& Fireman, 2007) or that different situations may lead to the same emotional experience (e.g. Pons \& Harris, 2005). Consequently, we expected more use of cognitive engagement by 7-8 year-olds than 5-6 year-olds and 3-4-year-olds.

'Attention' implies either diverting the target's attention away from an aversive event or making the target feel valued and cared for (Gross, 2006; Niven et al., 2009). Research showed that distraction is one of the earliest intrapersonal ER processes to appear in early childhood (Mischel \& Ayuduk, 2004; Rothbart, Ziaie, \& O’Boyle, 1992). Infants and young children use it to divert their own attention away from aversive events (e.g. Stifter \& Moyer, 1991) and instead focus on more pleasant events (Harris \& Lipian, 1989), but also to divert the attention of others (House, Henrich, Brosnan \& Silk, 2012). Making others feel valued and cared for is also present very early in childhood (from 2 years of age). However, it tends to decrease with age and is replaced by more complex strategies (McCoy \& Masters, 1985). Although research does suggest that the attention strategy is still used in adolescence and even adulthood (Gross, 2007), we expected this strategy to be used more by 3-4 year-olds compared to 5-6 year-olds and 7-8-year-olds, as older children might rely more on other strategies such us cognitive or affective engagement. 
Finally, 'humor' implies entertaining and amusing the target to make them laugh (Niven et al., 2009). This emotion regulation strategy has been reported equally in children (e.g. Dowling, 2001), adolescents (e.g., Erickson \& Feldestein, 2007), and adults (e.g., Nezlek \& Derks, 2001) to regulate one's own emotions. Therefore, we expect no age differences for this strategy.

Some studies found gender differences in children's intrapersonal ER abilities (e.g., Eschenbeck, Kohlmann \& Lohaus, 2007; Garnefski et al., 2004; Nolen-Hoeksema \& Aldao, 2011) whereas others did not (e.g., Barrett, Robin, Pietromonaco \& Eysell, 1998; McRae, Oschner, Mauss, Gabrieli \& Gross, 2008). We therefore entered gender as a control variable, but did not have any specific hypotheses as to gender differences.

\section{Method}

\section{Participants}

Sample 1 consisted of 180 parents who accepted to participate (78\% of people contacted) and report on their 3- to 8-year-old children. Sixty parents reported about children aged between 3 and 4 years $(M=46.03$ months; $S D=7.20$ months $) ; 60$ parents reported about children aged between 5 and 6 years $(M=71.05$ months; $S D=6.48$ months); and 60 parents reported about children aged between 7 and 8 years $(M=94.48$ months; $S D=6.94$ months). Within each age group 30 parents reported about a male child and 30 about a female child. In $99 \%$ of the cases the mother was the person who reported about the child. Parents were recruited from middle-class communities in southern England. If the family had more than one child, parents were asked to only report about the first-born child.

Sample 2 consisted of 126 children aged between 3 and 8 years who participated in this study. Forty-two children were between 3 and 4 years old $(M=44.21$ months; $S D=6.10$ months; 23 females); 42 children were between 5 and 6 years old $(M=70.10$ months; $S D=$ 
6.75 months; 21 females); and 42 children were between 7 and 8 years old $(M=92.69$ months; $S D=7.13$ months; 24 females). Children were from middle-class backgrounds and were recruited from three different schools in two large cities in Spain $(95 \%$ of the children in those schools received parental consent to participate in the study).

\section{Procedure}

The study received ethical clearance from the university's ethics committee. For Sample 1, parents of children falling into the age range required for the study were contacted through a participant database at the authors' institution. Once parents had consented to take part in the study a link to an online survey was sent. The questionnaire contained: (1) two demographic questions about the child's age and gender, (2) one question about any developmental delays (children with developmental delays were excluded from the data analysis), and (3) one open-ended question that asked parents to describe "one situation where your child was able to change what another person was feeling to make them feel better. If s/he is not able to do it please describe it as well".

For Sample 2, once parental consent was obtained, each child was tested individually. First, the child was presented with an open-ended question asking what they usually do to make someone feel better when they are feeling bad (general interpersonal ER). After that, children received a concrete scenario: Imagine your sibling or best friend is feeling bad because something bad happened to them. What would you do to make the sibling or best friend feel better (specific interpersonal ER)?

\section{Coding}

Participants' responses were coded into numerical values using the definitions of the different strategies (Niven et al., 2009) by two independent trained coders. Children's responses were translated into English using a back-translation method by a bilingual person not involved in this research. Each response was coded as either: affective engagement (i.e., 
any action that engage directly with the target's feelings), cognitive engagement (i.e., any action that engages with the target's cognitions in order to change their affect), attention (i.e., any action that implies giving the target consideration or diverting their attention away); and humor (i.e., amusing the target to improve their mood through acting silly, laughing, etc.). Please see Appendices B and C for examples of the responses coded within each category.

In Sample 1 only ten parents mentioned more than one strategy. When two strategies were mentioned only the first strategy was considered for analysis. In Sample 2 only ten children mentioned two different general interpersonal ER strategies and only six mentioned two different specific interpersonal ER strategies. In both samples, only the first strategy mentioned was coded. As part of their training, coders coded twenty randomly selected answers and then met to discuss and reach consensus. After the training, sixty responses, 20 per age group were coded reaching a good inter-rater reliability; $\kappa=.87$ for sample 1 and $\kappa$ $=.85$ for sample 2 .

\section{Statistical Analysis}

We aimed to analyze whether there was an interaction between the use of a strategy, the age of the child, and the gender. Given that all these variables were categorical, we performed hi-log-linear (hierarchical) and log-linear analyses (see Wickens, 1989). First, a saturated hierarchical log-linear (hi-log-linear) procedure was run to find the most parsimonious final model. The hi-log-linear procedure started from the saturated model which included all variables' main and interaction effects and thus fitted the data perfectly. In a backward-elimination procedure, interaction and main effects were removed from the saturated model, and the fit of the more parsimonious model was compared to the fit of the saturated model. The hi-log-linear procedure picked the model as the final model (1) that was more parsimonious than the saturated model and (2) whose model fit was not significantly different from the saturated model. Thus, a final model having a likelihood ratio value $\left(\chi^{2}\right)$ 
greater than $p=.05$ is considered to be fitting. It means that the expected frequencies are close to the observed frequencies (Wickens, 1989). The final model and its fit are reported in the text. To estimate the significance of specific main or interaction effects ( $z$ value parameter, partial $\chi^{2}$ ), a log-linear model was computed. For each strategy, variables included in the hilog-linear and log-linear analyses were Strategy [not used ( $r$, used], Age group [3-4 yearsold $(r), 5-6$ years-old and 7-8 years-old] and Gender [female $(r)$, male] with $r$ indicating the reference category of each factor for the $z$ value.

\section{Results}

Table 1 displays the frequency of strategy use by age for each sample. Overall, in both samples, 'affective engagement' was more common among 7-8 year-olds, followed by 'cognitive engagement'. 'Attention' was more common among 3-4 year-olds. 'Humor' had similar frequencies across the different age groups. We also conducted further analysis with the ER categories identified in previous literature. However, given that the focus of the paper is on the categories identified in the IAC model, these additional analyses are presented in Appendix D.

For the strategy affective engagement, the hi-log-linear analyses for Sample 1 produced the final model of Affective engagement $\times$ Age, $\chi^{2}=2.16, d f=6, p=.90$. The loglinear analysis (Table 2) showed that 7- and 8- and 5- and 6-year-olds used this strategy significantly more often than 3-and 4-year-olds. For Sample 2 in the general and the concrete scenario, we ran the analyses for the two eldest groups only because the cell frequency for the youngest group was lower than 5 (Table 1). The hi-log-linear analyses produced the final model of Affective engagement $\times$ Age (general scenario: $\chi^{2}=1.17, d f=4, p=.88$; concrete scenario: $\chi^{2}=2.58, d f=4, p=.63$ ). The log-linear analyses (Table 2) showed that 7 - and 8 year-olds used this strategy significantly more often than 5- and 6-year-olds. 
Regarding the strategy cognitive engagement, the hi-log-linear analyses for Sample 1 produced the final model of Cognitive engagement $\times$ Age, $\chi^{2}=3.46, d f=6, p=.75$. The loglinear analysis revealed that 7- and 8-year-olds used cognitive engagement strategies significantly more often than 3- and 4-year-olds. There was no significant age difference between the two youngest age groups (Table 2). For Sample 2, we ran the analyses for the two eldest groups only because the cell frequency for the youngest group was lower than 5 (Table 1). The hi-log-linear analyses produced the final model of Cognitive engagement $\times$ Age (general scenario: $\chi^{2}=4.08, d f=6, p=.66$; concrete scenario: $\chi^{2}=1.84, d f=4, p=.77$ ). The log-linear analyses showed that 7- and 8-year-olds used this strategy significantly more than the 5- and 6-year-olds.

Concerning the strategy attention, the hi-log-linear analyses for Samples 1 and 2 produced the final model of Attention $\times$ Age (Sample 1: $\chi^{2}=4.38, d f=6, p=.63$; Sample 2, general scenario: $\chi^{2}=3.86, d f=10, p=.95$; Sample 2, concrete scenario: $\chi^{2}=3.75, d f=6, p$ $=.71)$. The log-linear analyses showed significant differences between the three age groups. Three- and 4-year-old children used this strategy significantly more than children from the two older age groups.

Finally, for the strategy humor, the hi-log-linear analyses in both samples did not produce a significant model for any interaction, only the main effect of the category was significant (Sample 1: $\chi^{2}=4.08, d f=10, p=.94$; Sample 2, general scenario: $\chi^{2}=6.82, d f=$ 10, $p=.74$; Sample 2, concrete scenario: $\left.\chi^{2}=6.81, d f=10, p=.74\right)$. The log-linear analysis showed no significant age differences. When focusing on the content of humor, children mentioned the categories 'telling jokes', 'pulling silly faces' and 'making them laugh' to a similar extend (Sample 1: $\chi^{2}=.85, d f=4, p=.93$; Sample 2: $\chi^{2}=.32, d f=4, p=.98$ ).

\section{Discussion}


The present research investigated age differences in children's use of specific interpersonal affect-improving ER strategies, based on the classification of the interpersonal affect regulation (Niven et al., 2009). Results from both parent and child samples showed that there were indeed age differences in children's use of different strategies. As expected, in both samples, affective engagement strategies were more common in older children. This strategy requires emotion understanding (i.e., being able to represent others' emotional experiences as well as their causes and consequences) which improves with age (Payton et al., 2000). The same developmental pattern was found for cognitive engagement strategies which start to develop at the age of 4 and improve with age (Denham et al., 2012). This strategy involves emotion representation (Stegge et al., 2004), which may explain this developmental pattern. Attention strategies, however, were mainly used by younger children. This strategy implies either diverting a target's attention from an aversive event or valuing the target (e.g., material and physical comforting). Attention is quite simple in terms of cognitive demands, which may explain why it is mainly used by younger children. Given this simplicity it is possible that its use decreases with age as it does not target the "core" of the emotional experience (e.g., thoughts linked to an emotional state). Finally, we found no age differences in humor, consistent with previous literature on intrapersonal ER (Dowling, 2001; Erickson \& Feldestein, 2007). Niven et al.'s model mainly conceptualized humor as a form of distraction (e.g., Strick, Holland, van Baaren \& Knippenberg, 2009). However, previous research identified other forms of humor which are more oriented towards reappraising a negative emotional event (e.g., Martin, Puhlik-Doris, Larsen, Gray, \& Weir, 2003). When further analysing the content of the humor strategies both parents and children pointed out humor as a way to distract the target's attention away from the situation. Future research may explore whether humor conceptualized as reappraisal may only develop in older children and 
adolescents, given that reappraisal is more commonly used by older children and adolescents compared to younger children (e.g., Denham et al., 2012).

Overall, our results showed that even young children were able to use strategies (e.g., giving advice) that previous studies have only reported for older children (from 8 years onwards) (Denton \& Zarbatany, 1996; Rose \& Asher, 2004). This was particularly true when parents reported about their children. Thus, parents tend to perceive more 'mature' ER strategies than children themselves. Another variable that may explain the possible difference between parents' and children's reports may be that the samples were collected from different countries (i.e., UK, Spain); however, both countries represent western culture values. Although results were very similar future research should test whether culture may influence the potential use of certain strategies over others.

It is important to note that some of our predictions were based on the literature from intrapersonal ER (i.e., the use of strategies to change one's own mood), and in fact, the obtained results indicated a close correspondence between intrapersonal and interpersonal ER. This may be explained by simulation theories (Harris, 1991) according to which children establish a correspondence between their own and others' mental states or representations. In this sense, it is possible that children may use the same or similar interpersonal ER strategies that they would use to change their own mood. Future research may investigate the correspondence between the use of intrapersonal and interpersonal ER strategies.

Previous research reported mixed findings regarding gender effects in ER (e.g., Eschenbeck et al., 2007; Garnefski et al., 2004; McRae et al., 2008). This may be due to the different methods used. Generally, when using self-reports sex role stereotypes are more salient and hence, women tend to appear as more emotional than men (Fischer, 1993). In our research we found no gender differences. This may be explained due to the nature of the 
questions used, as the questions were more focused on what children usually do, rather than on what they believe they should do, which may increase the likelihood of the sex role stereotyping. Given that there is no literature available with regards to gender differences in interpersonal ER, future research should focus on the potential gender differences in strategy use.

Although our research tried to overcome some problems from previous studies, it has a main limitation as we relied exclusively on people's reports. It has been shown that what people report doing may differ from what they really do (e.g., Goldernberg, Matheson \& Mantler, 2006). Furthermore, relying on people's report may entail two other limitations. First, the impossibility of knowing what motivation underlies the strategy chosen. Second, the difficulty to determine whether certain strategies may not be used because they may be disregarded by the target of the regulation process (e.g., offering the target to be listened but being rejected). Therefore, future studies may benefit from an experimental approach relying on previous procedures from the domain of intrapersonal ER (e.g., Carthy, Horesh, Apter, \& Gross, 2010). Furthermore, our research was focused on interpersonal affect-improving ER. Although we decided not to include questions concerning affect worsening, we acknowledge that it may limit the general conclusions that can be drawn about developmental differences in interpersonal ER as a whole. Therefore, future studies should consider analysing age differences in the use of affect worsening strategies through observational or experimental procedures.

The obtained results may be not only due to age-related differences in social-cognitive abilities, but also due to children learning what strategies work better for specific contexts. Thus, children may acquire or start using other strategies as soon as they realise that they are efficient to lighten the target's mood. In fact, this would be consistent with Denham's (1998) findings concerning the development of intrapersonal ER, which showed that 
children were able to use a wide range of strategies depending on the target and the situation. Thus, future research may need to investigate the role of expectancies and learning in children's preferential use of strategies depending on the context.

Given the patterns obtained, future research could test whether positive engagement strategies (i.e., affective and cognitive engagement) are predominant in adulthood compared to attention strategies. We would expect this to be the case as positive engagement strategies require more complex cognitive functions, compared to the attention strategy. However, the use of a specific strategy may also depend on the emotional tone of the situation (see Web, Miles, \& Sheeran, 2012) and this could be a potential area to be targeted. Future research may also investigate the different developmental achievements that may drive changes in the use of different interpersonal ER strategies across the lifespan. Finally, future research could look at whether helping and sharing, as forms of prosocial behaviour may appear early as they do not target an emotional need and therefore they may involve less complex social-cognitive skills.

Despite these limitations, this research is a first step to broadening the scope of interpersonal ER in childhood and consolidating the study of this field. The study of interpersonal ER is particularly important as effective interpersonal ER has been shown to be a vital component for developing high-quality relationships in adulthood (Niven et al., 2012). Childhood is a period when people learn how to establish and maintain relationships with parents, peers and other authority figures, such as teachers (Fabes, Gaertner \& Popp, 2008). Studying what interpersonal ER strategies children use, may help researchers to gain a better understanding of how children establish and maintain high-quality relationships.

Our research is also a starting point for further studies to accurately map atypical interpersonal ER strategies in children of different ages. This could have practical and theoretical implications as it would allow teachers and health professionals to identify 
specific deficits in children's abilities to regulate others' emotions. By doing so it may be possible to design specific intervention programs to target these deficits. This could aid the detection and treatment of those disorders which show emotion dysregulation (i.e., deficits in ER) such as attention deficit hyperactivity disorder (ADHD) or borderline personality disorder (Schipper \& Petermann, 2013). Understanding age differences in the use of different interpersonal ER strategies in normally-developing children is a necessary first step to achieve this goal. 


\section{Compliance with Ethical Standards}

The authors do not have any conflict of interests. The research conducted has obtained ethical approval from the authors' institution and were in accordance to the 1964 Helsinki declaration and its later amendments or comparable ethical standards. It has been carried after obtaining informed consent from the participants. 


\section{References}

Barrett, L.F., Robin L., Pietromonaco, P.R. \& Eyssell K.M., (1998). Are women the "more emotional" sex? Evidence from emotional experiences in social context. Cognition \& Emotion, 12, 555-578.

Batson, C. D. (2011). Altruism in Humans. Oxford, NY: Oxford University Press.

Bilancia, S. D. \& Rescorla, L. (2010). Stability of Behavioural and Emotional problems over 6 years in children ages 4 to 6 or 6 to 7 at Time 1. Journal of Emotion and Behavioural disorders, 18, 149-161.

Burleson, B. R. (1982). The development of comforting communication skills in childhood and adolescence. Child Development, 53, 1578-1588

Carthy, T., Horesh, N., Apter, A., \& Gross, J.J. (2010). Emotional reactivity and cognitive regulation in children with Anxiety disorders. Journal of Psychopathology and Behavioral Assessment, 32, 23-36.

Coan, J. (2011). The social regulation of emotion. In J. Decety \& J. T. Cacioppo (Eds.), Handbook of social neuroscience, 614-623. New York: Oxford University Press.

Davis, M. H. (1994). Empathy: A social psychological approach. Madison, WI: Westview Press.

Denham, S. A. Bassett, H. H., Mincic, M.M., Kalb, S. C., Way, E., Wyatt, T., \& Segal, Y. (2012). Social-emotional learning profiles of preschoolers' early school success: A person-centered approach. Learning and Individual Differences, 22, 178-189.

Denton, K., \& Zarbatany, L. (1996). Age differences in support processes in conversations between friends. Child Development, 67, 1360-1373. 
Dooley, D., Whalen, C. K., \& Flowers, J. V. (1978). Verbal response styles of children and adolescents in a counseling analog setting: Effects of age, sex, and labeling. Journal of Counseling Psychology, 25, 85-95.

Dowling, J. S. (2002). Humor: A coping strategy for pediatric patients. Pediatric Nursing, 28, 123-131.

Dunfield, K. A., O’Connell, L., Kuhlmeier, V. A., \& Kelley, E. A. (2011). Examining the diversity of prosocial behaviour: Helping, sharing, and comforting in infancy. Infancy, $16,227-247$.

Eisenberg, N. (2000). Emotion, regulation and moral development. Annual Review of Psychology, 51, 665-697.

Eisenberg, N., \& Fabes, R. A. (1998). Prosocial development. In W. Damon, \& N. Eisenberg (Eds.), Handbook of child psychology: Vol. 3. Social, emotional, and personality development (5th ed., pp. 701-708). New York: Wiley.

Eisenberg, N., Fabes, R. A., Karbon, M., \& Murphy, B. C. (1996). Relations of school children's comforting behavior to empathy-related reactions and shyness. Social Development, 5, 330-351.

Eisenberg N., Shepard, S.A., Fabes. R.A., Murphy, B.C., \& Guthrie, I.K. (1998). Shyness and Children's Emotionality, Regulation, and Coping: Contemporaneous, Longitudinal, and Across-Context Relations. Child Development, 69, 767-790.

Eisenberg N, Smith CL, Sadovsky A, Spinrad TL. (2004). Effortful control: Relations with emotion regulation, adjustment, and socialization in childhood. In: R. F., Baumeister., editor. Handbook of self-regulation: Research, theory, and applications. Guilford Press; New York: pp. 259-282. 
Erickson, S.J. \& Feldstein, S.W. (2007). Adolescent humor and its relationship to coping, defense strategies, psychological distress and well-being. Child Psychiatry and Human Development, 37, 255-271.

Eschenbeck, H., Kohlmann, C.W., Lohaus, A. (2007). Gender differences in coping strategies in children and adolescents. Journal of Individual Differences, 28, 18-26.

Fabes, R. A., Gaertner, B. M. and Popp, T. K. (2008). Getting along with others: social competence in early childhood. In K. McCartney and D. Phillips (Eds.). Blackwell Handbook of Early Childhood Development. Oxford: Blackwell Publishing Ltd.

Farver, J. M., \& Branstetter, W. H. (1994). Preschoolers' prosocial responses to their peers' distress. Developmental Psychology, 30, 334-341.

Fischer, A.H. (1993). Sex differences in emotionality: fact or stereotype? Feminism \& Psychology, 3, 303-318.

Garnefski, N., Teerds, J., Kraaij, V., Legerstee, J., \& Van Den Kommer, T.(2004). Cognitive emotion regulation strategies and depressive symptoms, differences between males and females. Personality and Individual Differences, 36, 267-276.

Gross, J.J. (2007). Handbook of emotion regulation. New York: Guilford Press.

Harris, P.L. \& Lipian M.S. (1989). Understanding emotion and experiencing emotion. In C. Saarni, P.L. Harris (Eds.) Children's understanding of emotion. New York: Cambridge University Press, pp 241-258.

Hoffner, C., \& Haefner, M. J. (1997). Childrens comforting of frightened coviewers-Real and hypothetical television-viewing situations. Communication Research, 24, 136-152.

House, B. R., Henrich, J., Brosnan, S. F., \& Silk, J. B. (2012). The ontogeny of human prosociality: behavioral experiments with children aged 3 to 8. Evolution and Human Behavior, 33, 291-308. 
Larsen, J.T., To, J.T. \& Fireman, G. (2007). Children's understanding and experience of mixed emotions. Psychological Science, 18, 186-191.

Martin, R. A., Puhlik-Doris, P., Larsen, G., Gray, J., \& Weir, K. (2003). Individual differences in uses of humor and their relation to psychological well-being: Development of the Humor Styles Questionnaire. Journal of Research in Personality, 37, 48-75.McRae, K., Ochsner, K., Mauss, I.B., Gabrieli, J.D.J., \& Gross, J.J. (2008). Gender Differences in Emotion Regulation: An fMRI Study of Cognitive Reappraisal. Group Processes Intergroup Relations, 11,143-162.

McCoy, C. \& Masters, J. C. (1985). The development of children's strategies for the social control of emotion. Child Development, 56, 1214-1222.

Mischel, W. \& Ayduk, O. (2004). Willpower in a cognitive-affective processing system. In R. F. Baumeister \& K. D. Vohs (Eds.) Handbook of Self-Regulation: Research, Theory, and Application. New York, NY: Guilford Press; pp. 99-129.

Nezlek, J. B. \& Derks, P. (2001). Use of humor as a coping mechanism, psychological adjustment, and social interaction. Humor, 14, 395-413.

Niven, K., Totterdell, P., \& Holman, D. (2009). A classification of controlled interpersonal affect regulation strategies. Emotion, 9, 98-509.

Niven, K., Totterdell, P., Stride, C. B., \& Holman, D. (2011). Emotion Regulation of Others and Self (EROS): The development and validation of a new individual difference measure. Current Psychology: A Journal for Diverse Perspectives on Diverse Psychological Issues, 30, 53-73.

Nolen-Hoeksema. S., \& Aldao, A., (2011). Gender and age differences in emotion regulation strategies and their relationship to depressive symptoms. Personality and Individual Differences, 51, 704-708. 
Payton, J.W., Wardlaw, D.M., Grazyk, P.A., Bloodworth, M.R., Tompsett, C.J., \& Weissberg, R.P. (2000). Social and emotional learning: a framework for promoting mental health and reducing risk behaviours in children and youth. Journal of School Health, 70, 179185.

Persson, G. E. B. (2005). Young children's prosocial and aggressive behaviors and their experiences of being targeted for similar behaviors by peers. Social Development, 14, $206-228$.

Pons, F., \& Harris, P. (2005). Longitudinal change and longitudinal stability of individual differences in children's emotion understanding. Cognition \& Emotion, 19, 1158-1174.

Rholes, W.S., \& Ruble, D. N. (1984). Children's understanding of dispositional characteristics of others. Child Development, 55, 550-560.

Rimé, B. (2007). Interpersonal emotion regulation. In J. Gross (Ed.), Handbook of emotion regulation (pp. 466-485). New York, NY: Guilford Press.

Ritter, E. M. (1979). Social perspective-taking ability, cognitive complexity and listeneradapted communication in early and late adolescence. Communication Monographs, 46, $40-51$.

Roberts, W. \& Strayer, J. (1996). Empathy, emotional expressiveness, and prosocial behavior. Child Development, 67, 449-70.

Rothbart, M.K., Ziaie, H. \& O'Boyle. C.G. (1992). Self-regulation and emotion in infancy. New Directions for Child and Adolescent Development ,55, 7-23.

Rose, A. J., \& Asher, S. R. (2004). Children's strategies and goals in response to help-giving and help-seeking tasks within a friendship. Child Development, 75, 745-763.

Salovey, P., \& Mayer, J.D. (1990). Emotional intelligence. Imagination, Cognition, and Personality, 9, 185-211. 
Saarni, C. (1992). Children's emotional-expressive behaviour as regulators of others' happy and sad emotional states. New Directions in Child Development, 55, 91-106.

Schipper, M., \& Petermann, F. (2013). Relating empathy and emotion regulation: Do deficits in empathy trigger emotion dysregulation? Social Neuroscience, 8, 101-107.

Stegge, H., Terwogt, M.M., Reijnjes, A.H.A., \& Van Tijen, N. (2004). Children's conception of the emotion process: consequences for emotion regulation. In I. Nyklicek, L., Temoshok \& A., Vingerhoets (Eds.). Emotional expression and health: Advances in theory, assessment and clinical applications (pp. 240-254). New York: Brunner-Routledge.

Stifter, C.A., \& Moyer, D. (1991). The regulation of positive affect: Gaze aversion activity during mother-infant interaction. Infant Behavior and Development, 14, 111-123.

Strick, M., Holland, R. W., Van Baaren, R. B., \& Van Knippenberg, A. (2009). Finding comfort in a joke: Consolatory effects of humor through cognitive distraction. Emotion, 9, 574-578.

Thompson, R. (1994). Emotion regulation: A theme in search of definition. In N. Fox (Ed.), The development of emotion regulation: Biological and behavioural considerations. Monographs of the Society for Research in Child Development, 59 (2-3, Serial 240).

Zaki, J., \& Williams, W. C. (2013). Interpersonal emotion regulation. Emotion, 13, 803-810. 
Table 1

Frequencies of Interpersonal Regulation Strategies per Age Group

3-4 years-old 5-6 years-old $\quad$ 7-8 years-old

Sample 1 (Parents)

Affective engagement

$8(14 \%)$

$17(28 \%)$

$23(38 \%)$

Cognitive engagement

$5(9 \%)$

$12(20 \%)$

$20(33 \%)$

Attention

$40(67 \%)$

$22(37 \%)$

$8(13 \%)$

Humor

$6(10 \%)$

$9(15 \%)$

$9(15 \%)$

Telling jokes

$1(17 \%)$

$4(45 \%)$

$3(33 \%)$

Pulling silly faces

$3(50 \%)$

$2(22 \%)$

$2(22 \%)$

Making them laugh

$2(33 \%)$

$3(33 \%)$

$4(45 \%)$

Sample 2 (Children)

General Question

Affective engagement

$4(9 \%)$

$7(17 \%)$

$16(38 \%)$

Cognitive engagement

$1(2 \%)$

$5(12 \%)$

$13(31 \%)$

Attention

$27(64 \%)$

$19(45 \%)$

$5(12 \%)$

Humor

$10(24 \%)$

$11(26 \%)$

$8(19 \%)$

Telling jokes

$4(40 \%)$

$3(28 \%)$

$3(38 \%)$

Pulling silly faces

$4(40 \%)$

$4(40 \%)$

$2(20 \%)$

Making them laugh

$2(20 \%)$

$4(36 \%)$

$3(38 \%)$

Sample 2 (Children)

Concrete Scenario

Affective engagement

$4(10 \%)$

$7(17 \%)$

$15(36 \%)$

Cognitive engagement

$2(5 \%)$

$5(12 \%)$

$14(33 \%)$ 
Attention

Humor
$27(64 \%)$

$9(21 \%)$
$22(52 \%)$

$4(10 \%)$

$9(21 \%)$ 
Table 2

Results of Log-Linear Analyses for Regulation and Regulation Strategies

\begin{tabular}{|c|c|c|c|c|c|}
\hline Effects and interactions & $D f$ & Partial $\chi^{2}$ & $p$ & $\begin{array}{c}z \text { value } \\
\text { 3-4(r) 5-6- } \\
\text { year-olds }\end{array}$ & $\begin{array}{c}z \text { value } \\
3-4(\mathrm{r}) 7-8 \text {-year- } \\
\text { olds }\end{array}$ \\
\hline \multicolumn{6}{|l|}{ Sample 1 (Parents) } \\
\hline Affective engagement $\times$ Age & 2 & 30.84 & .001 & 2.91 & 5.15 \\
\hline Cognitive engagement $\times$ Age & 2 & 6.42 & .04 & 1.30 & 2.28 \\
\hline Attention $\times$ Age & 2 & 24.66 & .001 & -2.85 & -4.68 \\
\hline Humor $\times$ Age & 2 & .82 & .66 & .78 & .81 \\
\hline
\end{tabular}

Sample 2 (Children)

General Question

$\begin{array}{lccccc}\text { Affective engagement } \times \text { Age } & 1 & 4.02 & .04 & - & 1.99 \\ \text { Cognitive engagement } \times \text { Age } & 1 & 4.60 & .03 & - & 2.03 \\ \text { Attention } \times \text { Age } & 2 & 26.56 & .001 & -1.98 & -4.52 \\ \text { Humor } & 1 & 38.73 & .001 & - & .56\end{array}$

Concrete Scenario

.04

$\begin{array}{llllll}\text { Cognitive engagement } \times \text { Age } & 1 & 6.03 & .01 & - & 2.25\end{array}$

$\begin{array}{llllll}\text { Attention } \times \text { Age } & 1 & 26.10 & .001 & - & -4.49\end{array}$

$\begin{array}{llllll}\text { Humor } & 2 & .74 & .69 & .52 & .55\end{array}$ 
Note. The number of $z$ values corresponds to the degrees of freedom of the tested effects; $z$ values with absolute values greater than 1.96 are significant $(p<.05)$. 


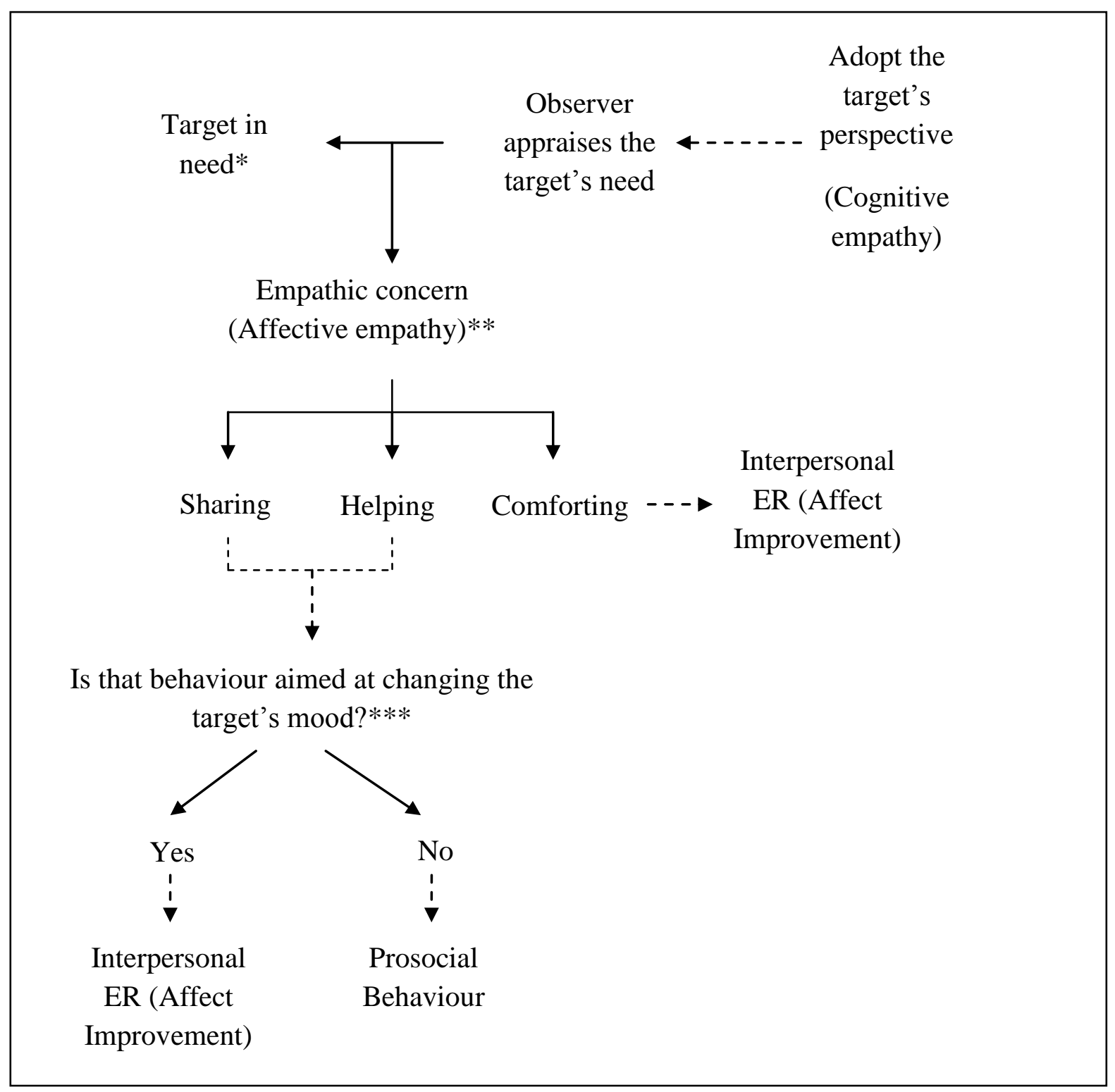

Figure 1. Model described to disambiguate the differences between interpersonal ER, empathic concern and prosocial behaviour

Notes:

* The target need may be physical, material or emotional.

**The empathic emotional experience could be different depending on how the agent appraises the target's need (e.g., empathic concern vs. personal distress).

***The motivation linked to those behaviours may be altruistic (i.e., aimed at improving the target's well-being), egoistic (i.e., aimed at obtaining self-benefit, such as social recognition) or both. 


\section{INTERPERSONAL EMOTION REGULATION}

Appendix A

Classification of Categories previously identified in the Literature within the Interpersonal Affect Classification Model

Interpersonal

Affect

Affective

Cognitive

Classification Engagement Engagement

Attention

Humor

Strategies

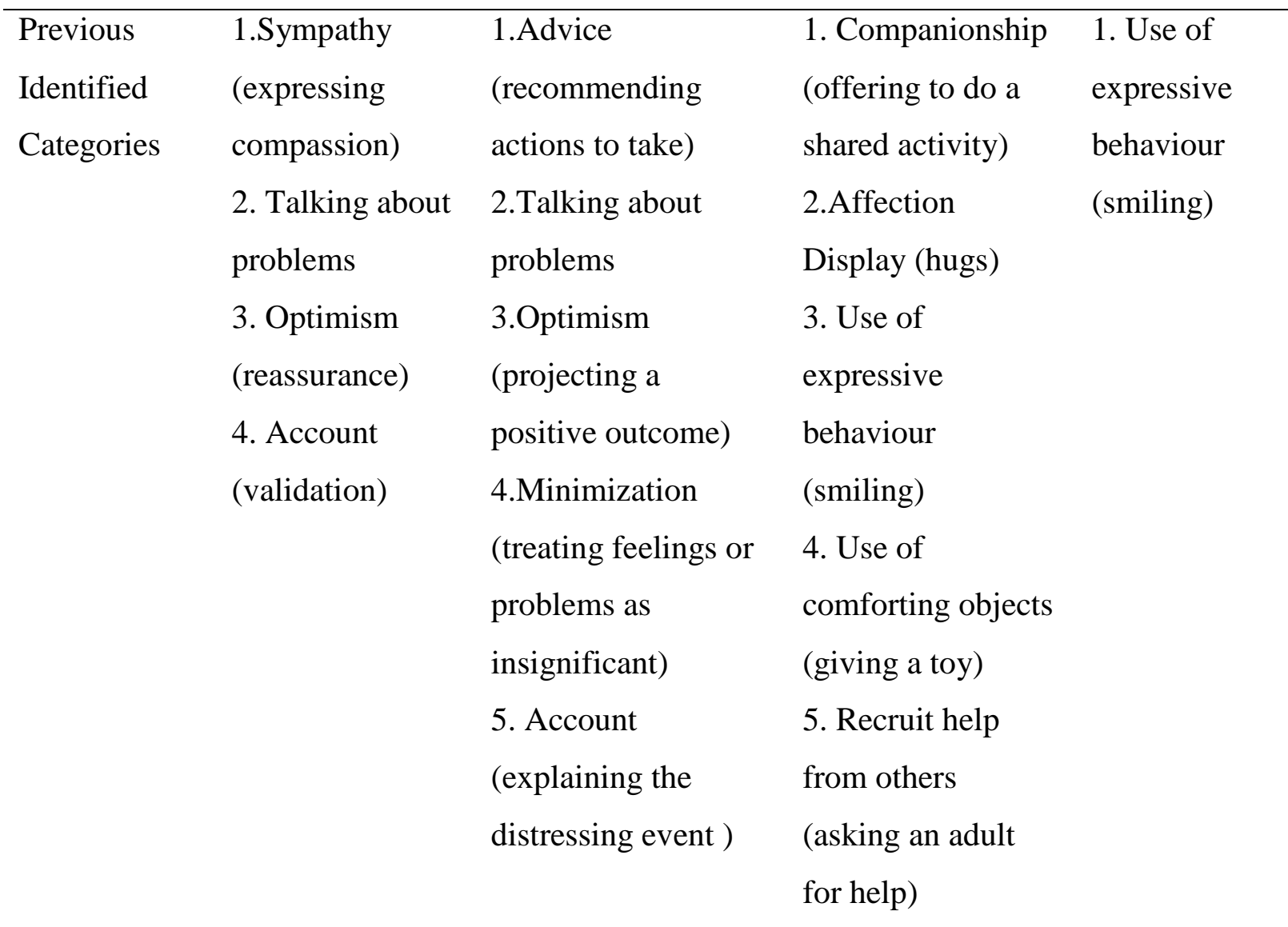


Appendix B

Example of Responses Coded in each Category in Sample 1

Name of the Definition $\quad$ Example of responses categorized

$\begin{array}{ll}\text { Strategy in each strategy } & \text { in }\end{array}$

(1) Affective $\quad$ Any action that engages $\quad$ - 'He comforted his sister who was

engagement directly with the target's sad by telling her kind words'

feelings (e.g., listening, - 'When I am upset she will try to

allowing the target to vent, $\quad$ cheer me up by listening to me'.

pointing positive

characteristics of the target)

(2) Cognitive $\quad$ To change the way a target $\quad$-'She told me not to worry about a

engagement thinks about a situation situation and think of ways to fix

through highlighting others' the problem'.

support, rationalizing, etc.

-'Once when I was upset he came

to me and put things into

perspective, so that I realised the

situation wasn't that bad'.

(3) Attention

Any action that implies

- 'I was poorly this weekend and

giving the target

she made me a get well soon card'.

consideration or diverting the

-'He fetched a toy and giving it to

target's attention from the

another child who was crying'.

situation

(4) Humor

Using humor to improve the

-'She plays the fool being silly to 
target's mood through acting cheer her sister or friends up'

silly, laughing, etc.

-'When seeing his brother was

upset he tried to cheer him up by

telling jokes and being silly to

make him laugh'. 
Appendix C

Example of Responses Coded in each Category for the General Question and the Concrete

Scenario in Sample 2

\begin{tabular}{|c|c|c|}
\hline Type of Question & Name of the Strategy & $\begin{array}{c}\text { Example of responses categorized in } \\
\text { each strategy }\end{array}$ \\
\hline \multirow{4}{*}{ General } & Affective engagement & $\begin{array}{l}\text { "I would tell them they are very nice } \\
\text { or that they did something fine" } \\
\text { "I would talk to them" }\end{array}$ \\
\hline & Cognitive engagement & $\begin{array}{l}\text { "I would tell them not to worry" } \\
\text { "I would say that everything would be } \\
\text { fixed at the end" }\end{array}$ \\
\hline & Attention & $\begin{array}{l}\text { "I would give them a kiss" } \\
\text { "I would tell them something about a } \\
\text { film I really like" }\end{array}$ \\
\hline & Humor & $\begin{array}{l}\text { "I would say something funny" } \\
\text { "I would put silly faces" }\end{array}$ \\
\hline \multirow{4}{*}{ Concrete Scenario } & Affective engagement & $\begin{array}{l}\text { "I would ask them about how they } \\
\text { feel" } \\
\text { "I would talk to them so they can feel } \\
\text { better" }\end{array}$ \\
\hline & Cognitive engagement & $\begin{array}{l}\text { "I would tell them that everything will } \\
\text { be fine" } \\
\text { "I would tell them they are not alone" }\end{array}$ \\
\hline & Attention & $\begin{array}{l}\text { "I would sit next to them to watch the } \\
\text { telly together" } \\
\text { "I would give them a picture as a } \\
\text { present" }\end{array}$ \\
\hline & Humor & $\begin{array}{l}\text { "I would tickle them to make them } \\
\text { laugh a lot" } \\
\text { "I would tell them some funny jokes" }\end{array}$ \\
\hline
\end{tabular}


Appendix D

Analyses of Interpersonal Emotion Regulation Categories Previously Identified in the

\section{Literature}

For the categories previously identified in the developmental literature, we only conducted analyses for the categories 'talking about problems', 'companionship', 'affective display', and 'use of comforting objects' as the frequencies were higher than 5. For 'talking about problems' in sample 1 , there was only a general effect of the category, $\chi^{2}=1.06, d f=1$, $p=.98$. Thus, there were no significant differences in the use of the strategy between 5-6 and 7-8-year olds (see Appendices E and F). We did not perform any analyses for Sample 2 as the frequencies were lower than 5 for at least two age groups. For 'companionship' $\left(\chi^{2}=.91, d f\right.$ $=1, p=.99)$ and 'affective display' $\left(\chi^{2}=.91, d f=1, p=.99\right)$, in sample 1 , there was only a general effect of the category. In sample 2, there was also a main effect of the category for 'companionship' ( $\left.\chi^{2}=1.08, d f=6, p=.98\right)$, affective display $\left(\chi^{2}=1.12, d f=6, p=.92\right)$, and use of comforting objects $\left(\chi^{2}=5.96, d f=6, p=.43\right)$. Thus, there were no significant differences in the use of the strategy for 3-4 and 5-6-year-olds (Appendix E). However, in sample 1, for 'use of comforting objects' the hi-log-linear produced a final model of Use of comforting objects $\times$ Age $\left(\chi^{2}=1.93, d f=4, p=.75\right)$. Thus, 3-4-year-olds used this strategy significantly more than 5-6-year-olds (Appendices E and F).

Overall, these results replicated previous findings. Whereas talking about problems was mainly used by older children, the use of comforting objects was mainly used by younger children, as previously found by McCoy and Masters (1985). Interestingly, although previous literature identified categories such as 'talking about problems', 'optimism', and 'account', according to the IAC model these categories may be classified at affective engagement if they entail only to engage with the target's feelings or cognitive engagement if they aim to change the target's mindset about the situation/problem. Thus, although previous categories may 
provide more fine-grained information the use of models such as the IAC may provide more information regarding the processes targeted by the strategy (i.e., expressive behaviour vs. cognition). Thus, rather than discarding previous categories, the recommendation should be considering different models when analysing children's ER strategies. 
Appendix E

Frequencies for Regulation Strategies Previously Identified in the Literature

\begin{tabular}{lll}
\hline 3-4 years-old $\quad 5-6$ years-old & 7-8 years-old
\end{tabular}

Sample 1 (Parents)

Affective engagement

\begin{tabular}{|c|c|c|c|}
\hline Sympathy & $4(32 \%)$ & $4(32 \%)$ & $5(38 \%)$ \\
\hline Talking about problems & $1(4 \%)$ & $10(42 \%)$ & $13(57 \%$ \\
\hline Optimism & $1(33 \%)$ & $1(33 \%)$ & $1(33 \%)$ \\
\hline Account & $2(25 \%)$ & $2(25 \%)$ & $4(50 \%)$ \\
\hline Cognitive engagement & $5(9 \%)$ & $12(20 \%)$ & $20(33 \%$ \\
\hline Advice & $0(0 \%)$ & $3(43 \%)$ & $4(57 \%)$ \\
\hline Talking about problems & $0(0 \%)$ & $2(50 \%)$ & $2(50 \%)$ \\
\hline Optimism & $1(9 \%)$ & $2(18 \%)$ & $8(73 \%)$ \\
\hline Minimization & $0(0 \%)$ & $0(0 \%)$ & $0(0 \%)$ \\
\hline Account & $4(27 \%)$ & $5(33 \%)$ & $6(40 \%)$ \\
\hline \multicolumn{4}{|l|}{ Attention } \\
\hline Companionship & $10(53 \%)$ & $7(37 \%)$ & $2(10 \%)$ \\
\hline Affective display & $10(42 \%)$ & $8(33 \%)$ & $6(25 \%)$ \\
\hline Use comforting objects & $20(69 \%)$ & $7(24 \%)$ & $2(6 \%)$ \\
\hline Recruit of help & $0(0 \%)$ & $0(0 \%)$ & $0(0 \%)$ \\
\hline
\end{tabular}

Humor

Use of expressive

$3(50 \%)$

$2(22 \%)$

$2(22 \%)$

behaviour

Sample 2 (Children) 
General Question

Affective engagement

$\begin{array}{lccc}\text { Sympathy } & 2(18 \%) & 3(27 \%) & 6(55 \%) \\ \text { Talking about problems } & 1(11 \%) & 2(18 \%) & 6(55 \%) \\ \text { Optimism } & 0(0 \%) & 0(0 \%) & 0(0 \%) \\ \text { Account } & 1(14 \%) & 2(29 \%) & 4(57 \%)\end{array}$

Cognitive engagement

$\begin{array}{llll}\text { Advice } & 0(0 \%) & 0(0 \%) & 3(100 \%) \\ \text { Talking about problems } & 0(0 \%) & 2(29 \%) & 5(71 \%) \\ \text { Optimism } & 1(11 \%) & 3(33 \%) & 5(56 \%) \\ \text { Minimization } & 0(0 \%) & 0(0 \%) & 0(0 \%) \\ \text { Account } & 0(0 \%) & 0(0 \%) & 0(0 \%)\end{array}$

Attention

$\begin{array}{lccc}\text { Companionship } & 9(45 \%) & 8(40 \%) & 3(15 \%) \\ \text { Affective display } & 8(50 \%) & 6(37 \%) & 2(13 \%) \\ \text { Use of comforting } & 10(67 \%) & 5(33 \%) & 0(0 \%) \\ \text { objects } & 0(0 \%) & 0(0 \%) & 0(0 \%) \\ \text { Recruit of help } & \end{array}$

Humor

Use of expressive

behaviour

$4(40 \%) \quad 4(40 \%) \quad 2(20 \%)$ 
Appendix F

Results of Log-Linear Analyses for Regulation and Regulation Strategies

\begin{tabular}{lccccc}
\hline Effects and interactions & $D f$ & Partial $\chi^{2}$ & $p$ & $z$ value & $z$ value \\
& & & $3-4(\mathrm{r}) 5-6-$ & $3-4(\mathrm{r}) 7-8$-year- \\
& & & year-olds & olds
\end{tabular}

Sample 1 (Parents)

Affective engagement

$\begin{array}{lllllll}\text { Talking about problems } & 1 & 49.08 & .001 & - & .70\end{array}$

Attention

\begin{tabular}{|c|c|c|c|c|c|}
\hline Companionship & 1 & 67.36 & .001 & -.77 & - \\
\hline Affective display & 1 & 107.07 & .001 & -.55 & -1.10 \\
\hline $\begin{array}{l}\text { Use of comforting objects } x \\
\text { Age }\end{array}$ & 1 & 8.65 & .003 & -2.81 & - \\
\hline
\end{tabular}

Sample 2 (Children)

General Question

Cognitive engagement

$\begin{array}{lllll}\text { Companionship } & 1 & 31.83 & .001 & -.27 \\ \text { Affective display } & 1 & 40.75 & .001 & -.45 \\ & & & & \\ \text { Use of comforting objects } & 1 & 37.60 & .001 & -1.33\end{array}$

Note. The number of $z$ values corresponds to the degrees of freedom of the tested effects; $z$ values with absolute values greater than 1.96 are significant $(p<.05)$. 